\title{
PERFORMANCE ANALYSIS OF CYLINDRICAL TYPE AIR EJECTOR
}

\author{
W. A. Aissa \\ Mechanical Power Department, High Institute of Energy, South Valley \\ University, Aswan, Egypt. \\ Tel: +[20] 97 481234,481235_E-mail: walid_aniss@yahoo.com
}

(Received March 11, 2006 Accepted April 19, 2006)

\begin{abstract}
Performance tests were conducted for an air ejector entraining two secondary jets whose axes are coaxial of that of primary stream. A unique ejector housing was constructed to receive both the convergent or convergent-divergent primary nozzle and the cylindrical mixing chamber. The air ejector under investigation has nozzle throat-tocylindrical section area ratio of 0.12. The investigation is conducted for ejector having cylindrical length-to-diameter ratio, which varies from 2.31 to 23.08. It covers a range of spacing from -1 to 0.5 of cylindrical lengths and of secondary to ambient pressure ratio of 1.0. The recorded axial distributions of the static wall pressure are plotted in nondimensional forms and the extent of consistency of the profiles is shown. The induced air flow rate ratio is plotted for the measured primary to secondary stagnation pressure ratio range. Results offered a valuable appreciation of the effect of the cylindrical length and nozzle spacing-todiameter ratios on both wall pressure distribution and jet entrainment capacity. The occurrence of flow choking in both the convergent or convergent-divergent primary nozzle was ensured.
\end{abstract}

KEYWORDS: air-ejector, cylindrical length, spacing

\section{INTRODUCTION}

Historically [1], several different types of devices have been given the generic name "ejector" simply because they rely upon the induction of a quantity of secondary fluid from a lower to a higher pressure into a duct by some form of interaction with a primary stream fluid in the duct.

The main function of the ejector is to entrain the maximum secondary flow at any given primary operating condition and to compress the entrained mass within the ejector to the required discharge condition [2]. The higher the secondary flow, the larger is the energy saving potential of the system. Therefore, the secondary to the primary mass flow rate ratio, $W s / W_{P}$ can be assumed as large as required if adequate pumping can be achieved in the ejector. Therefore, a good understanding of the ejector entrainment capability is critical in its design and operation. 


\section{NOMENCLATURE}

\begin{tabular}{llll}
$d$ & Diameter & \multicolumn{2}{l}{ Abbreviations } \\
$D$ & Cylinderical section diameter & $C$ & Convergent \\
$l$ & Length & $C-D$ & Convergent-divergent \\
$L$ & Cylindrical section length & \multicolumn{2}{l}{ Subscripts } \\
$P$ & Pressure & $b$ & Back \\
$S$ & Nozzle spacing & $c$ & Convergence \\
$T$ & Absolute temperature & $d$ & Divergence \\
$V$ & Velocity & $D$ & Diffuser \\
$W$ & Mass flow rate & $m$ & Mixture \\
$\bar{W}$ & Mass flow rate ratio; $=W_{S} / W_{P}$ & $p$ & Primary, pipe \\
$x$ & Axial distance measured from nozzle & $s$ & Secondary \\
& exit plane & $t$ & Throat \\
$\Delta p_{x, r}$ & Pressure parameter, $\Delta \mathrm{p}_{\mathrm{x}, \mathrm{r}}=\left(\mathrm{P}_{\mathrm{x}}-\mathrm{P}_{\mathrm{os}}\right) /$ & $x$ & Axial distance measured \\
& (P $\left.\mathrm{P}_{\mathrm{op}}-\mathrm{P}_{\mathrm{b}}\right)$ & & from nozzle exit plane \\
$\alpha$ & Cone angle & $R$ & Ratio \\
$\gamma$ & Ratio of specific heats & 0 & Stagnation \\
$\eta$ & Efficiency of air ejector & &
\end{tabular}

The ejector configuration [2] consists mainly of four parts, primary nozzle, entrance (suction) section, mixing section, and diffuser. In the ejector, the kinetic energy of the primary fluid is used to create a low pressure in the suction chamber by entraining the secondary fluid stream. The mixing of the two fluid streams occurs in the mixing chamber of the ejector, and the resultant mixture is compressed downstream out of the diffuser. The system is inferior in efficiency compared to a fan [3]. However, its advantages lie in its simplicity, ease of operation and rugged construction, having no moving parts and requiring less maintenance, has a long life and sustains its efficiency even when handling corrosive or dusty fluid streams.

The development and physics of the shear-mixing layer, which serves to entrain the secondary mass flow and mix it with the primary stream, may be attributed as follows. Downstream of the exit plane of the primary nozzle, the jet tends to spread towards the ejector wall and there exists a thin shear layer between the primary and secondary flows. The secondary flow which is bounded by the solid wall of the ejector and the shear mixing layer would be accelerated by the driving shear force and the primary flow would be retarded through the shear mixing layer due to the velocity gradient. Thus, this shear layer seems to be a "barrier" impeding mass, energy, and momentum exchange between the streams. The distance to which the thin shear layer extends downstream of the primary nozzle exit is difficult to determine. As was indicated in [3], the characteristics of the shear-mixing layer associated with the vortices and hence the performance of an ejector with specific geometry over a range of operating conditions is governed by the primary (jet) behavior.

The topic of ejectors has been extensively studied [1-7]. An analysis of the flow of compressible fluids through a thrust augmenting ejectors under the assumption that the mixing process occurs in a constant cross section duct was presented [1]. 
Industrial ventilation employing air-air ejector connected to a compressed-air line was investigated [2]. The results indicated the influence of the primary pressure and pressure ratio on jet entrainment capacity and efficiency.

The occurrence of flow choking in an ejector system was analyzed and a model for predicting the maximum flow ratio of the ejector was developed and validated with experimental data [3]. A theoretical analysis, which is based on simplified, one-dimensional model of constant area mixing, was utilized to predict the performance of supersonic-supersonic ejectors [4]. It was indicated that the theoretical maximum compression ratios are $15-22 \%$ higher than the measured values.

An investigation was conducted on several auxiliary inlets located in the fuselage boundary layer and supply secondary air flow to ejector exhaust nozzles at free stream Mach numbers of 0.64, 1.5, 1.8 and 2.0 [5]. Aissa [6] conducted an experimental work to study the effect of introducing multiple (three, four and five) nozzles with and without swirl instead of one nozzle in the primary stream on air ejector performance at low (2.5-5.0) primary-to-secondary stagnation pressure ratios and different throat length-to-diameter ratios.

Okai et al [7] performed experiments and numerical calculations on the flow field of a model ejector ramjet to investigate fundamental fluid dynamic aspects of its shear and mixing effect. They also investigated the enhancement of mixing of the primary flow and the entrained secondary flow with downstream pressure rise.

Above literature suggests that studies on air ejector performance may be grouped under two general approaches [2]. The first is to develop analytical models of flow mixing and entrainment and to test the accuracy of the formulation against actual experimental results. The other approach is to construct prototype for tests under very specific operating conditions. Hardly any information exists on the performance of ejectors operating with relatively low primary pressures.

The present investigation lies in the second category. Its purpose is to establish the performance of various ejector configurations designed to operate at relatively low primary pressure to pump moderate quantities of secondary air (from 10 to 50 percent of the primary quantity for various cylindrical lengths and nozzle spacing -to-diameter ratios. Both sonic (convergent) nozzle and supersonic (convergent-divergent) nozzles are used. The nozzles have 0.12 nozzle throat-to-mixing chamber cylindrical area ratio.

In this study, the flow entrainment ratios were expressed in terms of the mass flow rate as a percentage of primary air quantity. Absolute pressures are used throughout this paper. Flow entrainment and evacuation occurred under atmospheric conditions. For all practical purposes, the ratio of stagnation temperatures of secondary to primary streams may be taken as unity.

\section{EXPERIMENTAL TEST SETUP}

\subsection{Air Jet Ejector Test Loop}

Air jet ejector test loop is used to supply, control, and measure the flow rates of both primary and secondary streams and to measure primary and secondary temperatures and pressures. The test loop shown in Fig. 1 consists of air jet ejector test section, air supply unit and measuring instruments. 


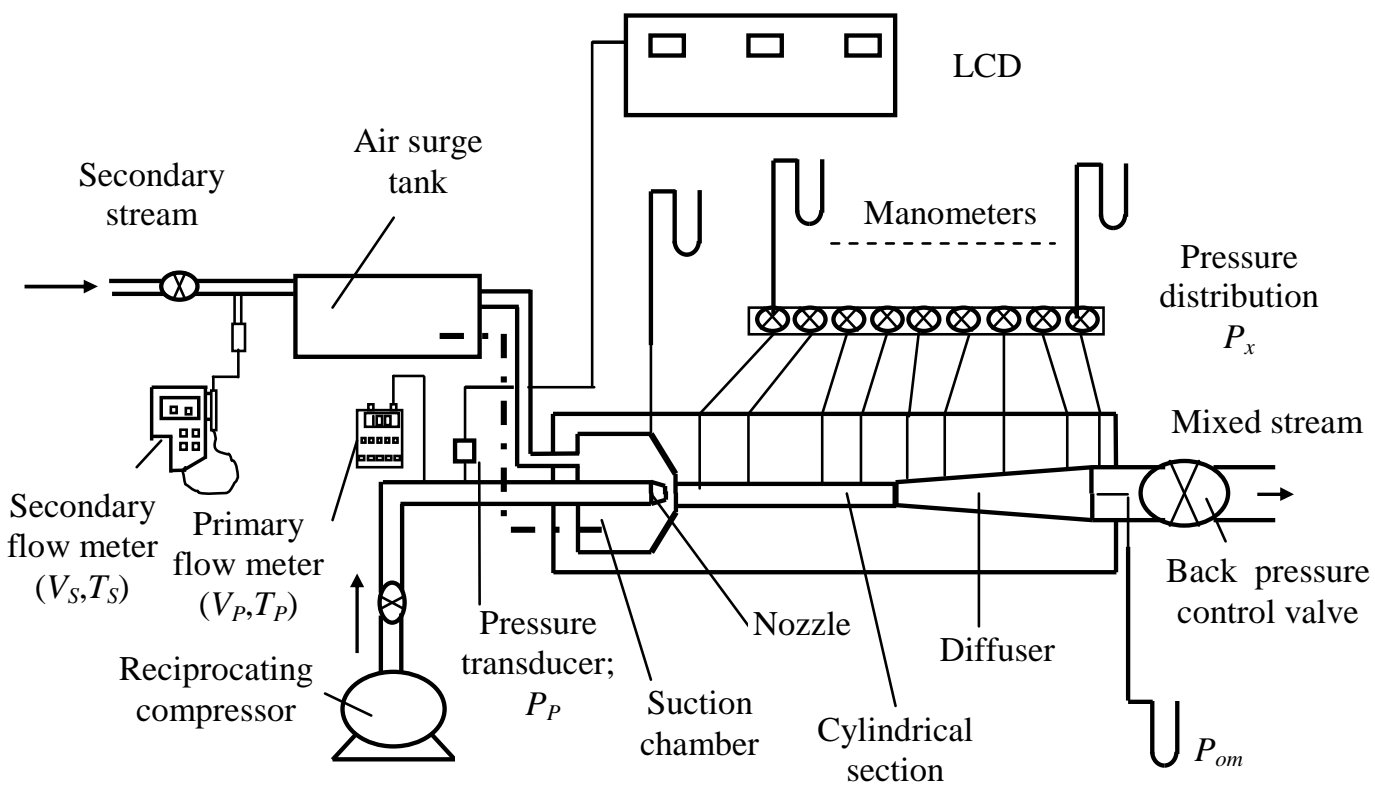

Figure 1: Test stand and instrumentation.

2.1.1. Air jet ejector test section: It is a duct system made up of an axisymmetric nozzle arrangement; with a flow passage for primary and secondary streams and it consists of:

1. Suction chamber

2. Cylindrical section: Combinations of a set of six transparent Perspex parts having $13 \mathrm{~mm}$. inner diameter; $D$; Fig. 2, and various lengths are assembled to form cylindrical sections of $2.31,6.92,11.54,13.85,16.15,18.45,20.77$ and 23.08 cylindrical length-to-diameter ratios; $L / D$, respectively.

3. Diffuser of a $39-\mathrm{mm}$ length; $l_{\mathrm{D}}$ and $7^{\circ}$ full divergence cone angle; $\alpha_{D}$. It is made of Perspex.

4. Nozzle: Two brass nozzles are used, convergent ( $\mathrm{C}$ ) with $4.5 \mathrm{~mm}$ throat diameter $\mathrm{d}_{\mathrm{t}}$ and $20^{\circ}$ convergence cone angle; $\alpha_{\mathrm{c}}$ and convergent-divergent ( C-D) with $4^{\circ}$ divergence cone angle; $\alpha_{d}$ and $5.0 \mathrm{~mm}$ exit section diameter; $\mathrm{d}_{\mathrm{d}}$.

5. Pipe connection system, Air is compressed from the compressor to the ejector through a $28.4 \mathrm{~mm}$ inner diameter pipe; $d_{P}$. Primary and back- pressures are controlled using valves fitted downstream the compressor and diffuser respectively.

6. Surge tank: A 10 liters air tank is fitted to damp the fluctuation of the secondary pressure to the ejector.

Secondary stream enters the suction chamber via two tubes coaxial with the nozzle centerline, both having $10 \mathrm{~mm}$ inner diameters; $d_{S}$. Suction pressure is controlled using a valve connected downstream the surge tank. 


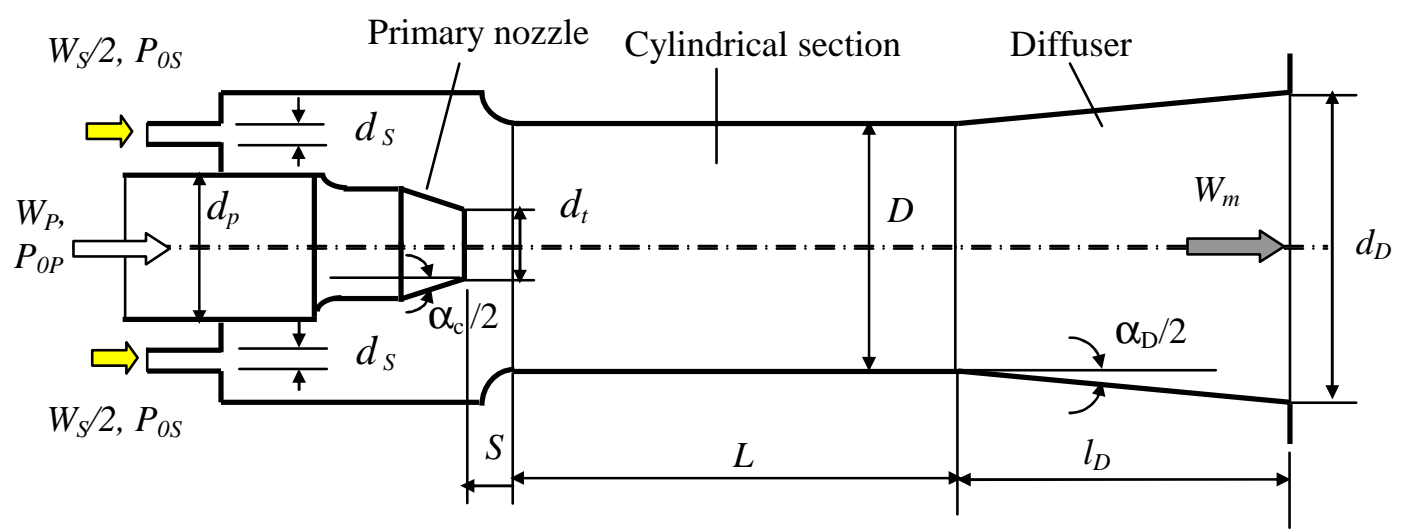

a) Air jet ejector test section with convergent primary nozzle

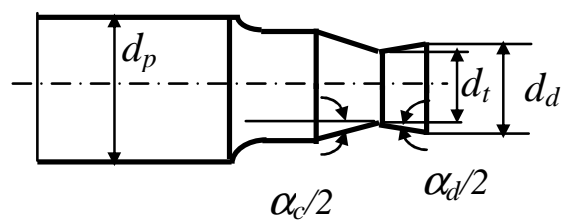

b) Convergent-divergent primary nozzle

Figure 2: Air jet ejector test section.

2.1.2. Air supply unit: $1.5 \mathrm{HP}$ reciprocating compressor is used to supply the primary air stream. Temperature range is from -10 to $+50^{\circ} \mathrm{C}$. Maximum pressure is 11.76 bar.

\subsubsection{Measuring instruments}

The flow rate, pressure and temperature are measured using primary and secondary flow meters, pressure transducer and manometers as discussed in Reference [9].

\subsection{Experimental Procedure}

Each series of tests began with zero nozzle spacing (i.e. $S=0$ ), a specific cylindrical length, and a specified stagnation primary pressure; $P_{O P}$ and keeping both the secondary and back pressure control valves fully open. This arrangement should increase the static pressure both at the secondary fluid suction chamber; $P_{S}$, and at the discharge side. The series of tests were repeated for primary stagnation pressures varying from 1.5 to 3.0 bar and with the supply air mass flows varying from 20 to $41.5 \mathrm{~kg} / \mathrm{hr}$. The cylindrical length was increased in steps by adding cylindrical sections and tests are performed to explore the effect of cylindrical length on the performance of the ejector. Another group of tests is conducted for the ejector with convergent 
primary nozzle and having 11.54 cylindrical length-to-diameter ratio in order to investigate the effect of nozzle spacing on the ejector performance. During the tests, the primary to secondary stagnation pressure ratio was varied from 3 to 7 , resulting in the variation of the supply air mass flow rate from 41.5 to $84.96 \mathrm{~kg} / \mathrm{hr}$. The cylindrical section was moved axially relative to the nozzle exit section to achieve nozzle spacing to cylindrical length ratio of -1.0 to 0.5 . All tests were done with the secondary and back pressures equal that of ambient.

\section{RESULTS AND DISCUSSION}

\subsection{Effect of Cylindrical Length}

A series of experiments was conducted for the ejector for both $\mathrm{C}$ and $\mathrm{C}-\mathrm{D}$ primary nozzles with varying cylindrical length-to-diameter ratio. The data for each configuration are plotted non-dimensionally in Figs. $\mathbf{3}$ to $\mathbf{8}$ for primary stagnation pressures varying from 1.5 to 3.0 bar. Mach number at nozzle exit of primary stream was 1.0 for C primary nozzle and 1.58 for C-D nozzle, verifying choked nozzle condition. At the section corresponding to primary nozzle exit section, secondary stream Mach number was found to vary with primary stagnation pressure from 0.035 to 0.066 for $\mathrm{C}$ primary nozzle and from 0.032 to 0.053 for C-D primary nozzle for the whole range of cylindrical length-to-diameter ratio range measured. Mixture flow was subsonic.

The effect of pressure ratio on mass-flow ratio for ejector configuration is of great significance. Figures $\mathbf{3}$ and $\mathbf{4}$ show plots of mass-flow ratio; $\bar{W}$ against cylindrical length-to-diameter ratio for both $\mathrm{C}$ and C-D nozzles and various values of primary to secondary stagnation pressure ratios.

It is generally known that, for a specified configuration, the mass flow rate of a primary nozzle increases as the primary stagnation pressure increases until the maximum mass-flow rate of the ejector is reached. Beyond this point, the mass flow rate is independent of the primary stagnation pressure and remains constant due to

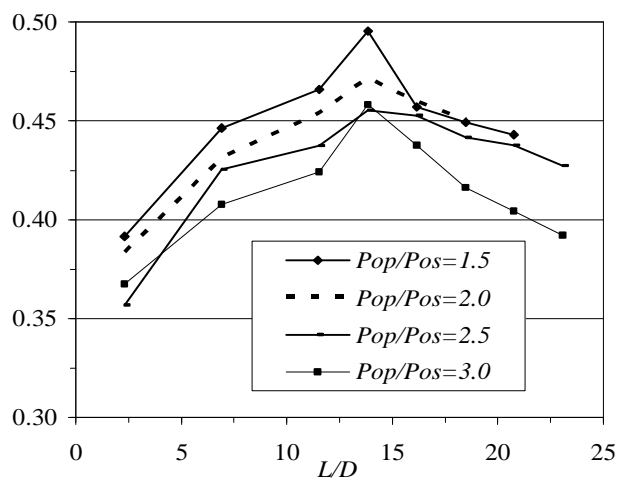

Figure 3: Mass-flow ratio variation with Cylindrical length, $C$ Nozzle, $S / D=0.0$.

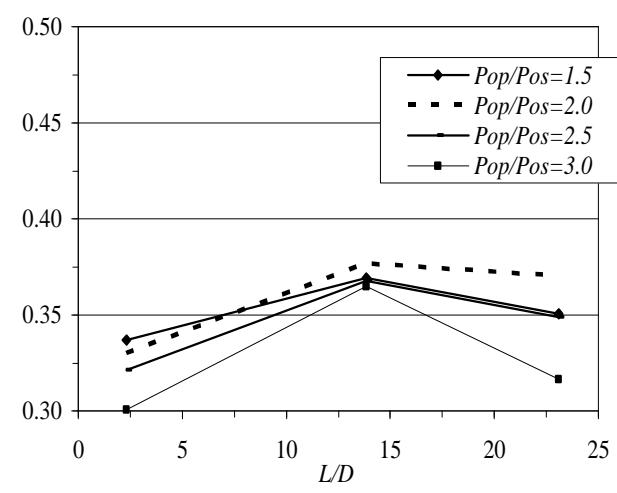

Figure 4: Mass-flow ratio variation with Cylindrical length, C-D Nozzle, $S / D=$ 0.0 . 
choking inside the ejector [2]. As expected, increasing primary mass flow rate, for a specific cylindrical length-to-diameter ratio, entrains more secondary flow up to a certain limit.

The figures illustrate that in general, for a specific cylindrical-length-todiameter ratio, the mass-flow ratio decreases with increasing stagnation pressure ratio. This may be attributed to the fact that both the primary and secondary mass flow rates increase with increasing the primary pressure. However, the rate of increase of secondary mass flow rate is lower than that of primary flow. This trend, as stated in reference 2 is apparently caused by a change in the primary-jet-stream configuration, which progressively fills more of the mixing-section area thereby blocking, to varying degrees, the secondary flow. This phenomenon occurred quite consistently in the experiments but with varying effectiveness. This matches with the findings presented in [5].

Moreover, it may be concluded that for a specific primary pressure, the massflow ratio increases with increasing the cylindrical length-to-diameter ratio and then decreases with further increase in the cylindrical length-to-diameter ratio for both $\mathrm{C}$ and C-D primary nozzles. The cylindrical length-to-diameter ratio corresponding to peak mass flow rate ratio $(L / D=13.85)$ may be considered an optimum value.

The decrease of secondary mass flow rate beyond the value corresponding to the optimum cylindrical length-to-diameter ratio may be attributed to frictional losses and the nozzle being unable to produce the desired momentum exchange between the primary and secondary fluid streams at the shear mixing layer.

The variation of the measured axial wall pressure distributions for several values of the primary to secondary stagnation pressure ratio is shown in Figs. 5-8 in the form of the non-dimensional pressure parameter; $\Delta p_{x, r}=\left(P_{x}-P_{o s}\right) /\left(P_{o p}-P_{b}\right)$ against longitudinal distance to nozzle throat diameter ratio; $x / d_{t} ; P_{b}$ is the back pressure.

Because the static pressure of the secondary stream is ordinarily lower than that of the primary for the station at the primary nozzle exit plane, the primary stream expands as it leaves the nozzle. Because this expansion reduces the secondary stream area along the flow direction and for an assumed low back pressure, the secondary stream accelerates and, if it is assumed that little energy exchange occurs, the secondary stream pressure decay causes a further expansion of the primary stream, this may indicate the pressure variation illustrated in Figs. 5-8.

Comparing Figs. 5, 6 and 7, 8, it appears that the pressure distribution for ejector with C-D nozzle is lower than that of the corresponding C nozzle ejector. This may be attributed as follows, by further expanding the primary stream; for a fixed secondary inlet stagnation pressure, to obtain higher values of primary Mach number at primary nozzle exit; $M_{\mathrm{P}}$, the corresponding primary static pressure is decreased which may lead to separation of the secondary stream. This is associated with a reduction in the ejector performance represented by the decrease of the pressure distribution.

It may be observed from Figs. 5 and $\mathbf{7}$ that for both convergent and convergent-divergent nozzles, the wall pressure increases with increasing the stagnation pressure ratio. This trend, which matches the findings presented in reference 4 may be attributed to higher momentum. 


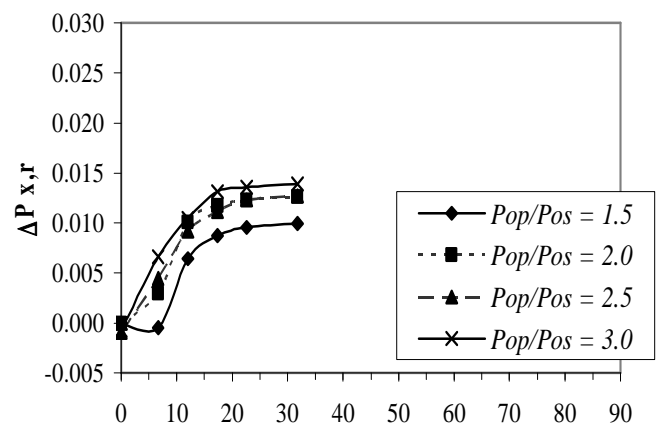

$x / d_{t}$

Figure 5 : Wall static pressure distribution, C primary nozzle, $L / D=2.31, S / D=0.0$.

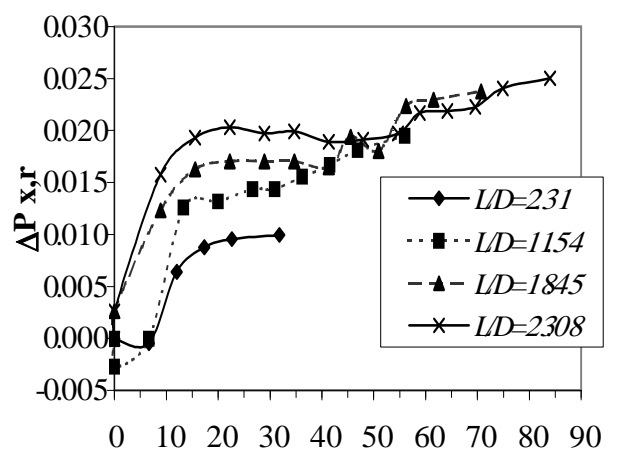

$x / d_{t}$

Figure 6: Wall static pressure distribution, $C$ primary nozzle, $P_{O P} / P_{O S}=$ $1.5, S / D=0.0$

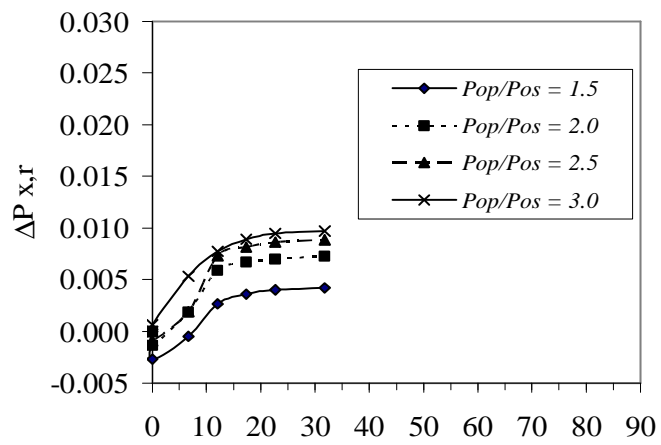

$x / d_{t}$

Figure 7 : Wall static pressure distribution, C-D primary nozzle, $L / D=2.31, S / D=0.0$.

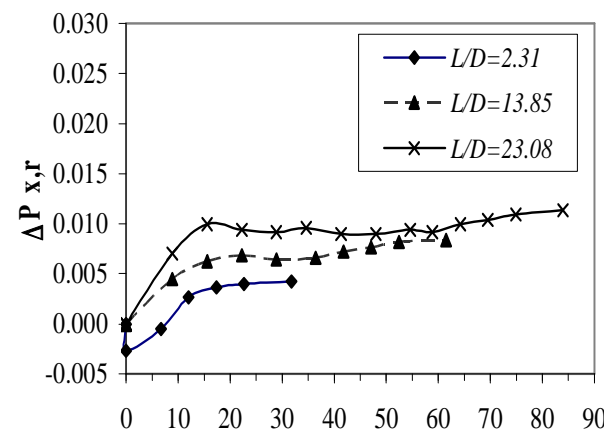

$x / d_{t}$

Figure 8: Wall static pressure distribution, C-D primary nozzle, $P_{O P} / P_{O S}=1.5, S / D=0.0$.

Further appreciation of the influence of the length-to-diameter ratio is given in Figs. 6 and 8. For the cylindrical length-to-diameter ratios employed, $L / D=2.31$, $11.54,18.45$ and 23.08 the corresponding end section location of the mixing chamber times the nozzle throat diameter has values of $6.67,30.89,45.55$ and 58.89, respectively.

Curves which correspond to $L / D=2.31$, and 11.54 in Fig. 6, indicate that the wall pressure exhibits an initial rise followed by a nearly linear slow increase to the exit. The initial pressure rise can be attributed to the diffusion of the secondary stream as it is compressed by the primary stream in the initial interaction region. It appears that the static pressure is still rising at the tube exit. Thus, it appears that the mixing tube was not of sufficient length for the diffusion process to be completed. 
For all configurations employed, the pressure is seen to rise through the cylindrical section. For the ejector having longer cylindrical section $L / D>11.54$, the pressure drops before the diffusion, indicating that the mixing chamber may be too long as indicated by Chou [3] who reported that the best length-to-diameter ratio is about 14 for optimum performance at higher pressure ratios and lower mass-flow ratios (which is close to the value obtained by performance curves in the current investigation $=13.85)$. Hence, the optimum cylindrical length-to-diameter ratio obtained by pressure distribution $(=11.54)$ is under estimated compared to that obtained by performance mass ratios curves.

\subsection{Effect of Nozzle Spacing}

The effect of primary to secondary stagnation pressure ratio on mass-flow ratio for a fixed configuration is of great significance. These effects are shown in Figs. 9 and 10 as mass-flow ratio against $P_{O P} / P_{O S}$ for different spacing ratios; $S / D$. Spacing; $S$ is defined as the distance measured axially from the exit plane of the primary nozzle to the inlet plane of the mixing cylindrical section.

It may be concluded from Fig. 9 that in general the mass-flow ratio decreases with increasing stagnation pressure ratio. This effect agrees with the findings presented earlier in Figs. $\mathbf{3}$ and $\mathbf{4}$ and to an extent with varying nozzle spacing.

Figure 10 shows the mass-flow ratio plotted against the spacing ratio; $S / D$ at various primary to secondary stagnation pressure ratios. The form of the profiles is almost Gaussian. The spacing that produces the maximum mass flow ratio is unchanged by a change in primary to secondary stagnation pressure ratio beyond a value of 4.0. There is a slight decrease in spacing for maximum mass-flow ratio with decreasing primary to secondary stagnation pressure ratio. Reference 3 indicated that the optimum nozzle position is attained when the primary flow spread impinges at the leading edge of the cylindrical section. If the primary nozzle is located upstream of the optimum location, i.e. far from the cylindrical section, the primary flow impinges on the chamber wall of the entry section. This results in the reflection of part of the flow, thus hindering entrainment. When the primary nozzle is located closer to the

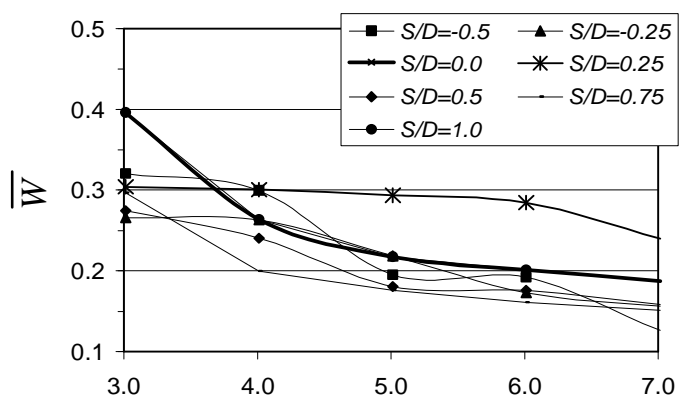

$$
\boldsymbol{P}_{\text {oP }} / \boldsymbol{P}_{\text {os }}
$$

Figure 9: Mass-flow ratio variation, C primary nozzle, $L / D=11.54$.

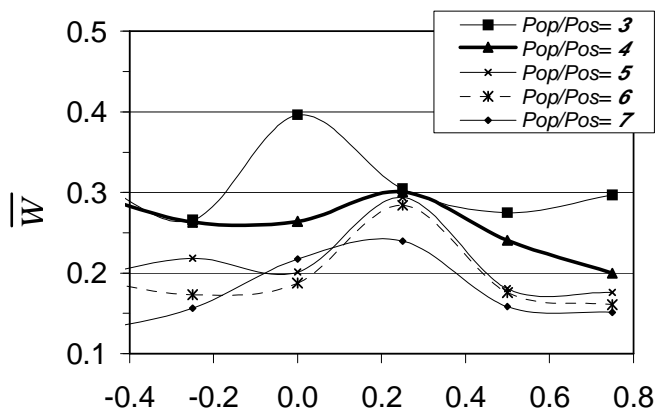

$S / D$

Figure 10: Effect of nozzle spacing on mass flow ratio, $C$ primary nozzle, $L / D$ $=11.54$. 
cylindrical section, i.e. further downstream of the optimum location, the distance for flow mixing is relatively short resulting in a loss of entrainment as a whole. It may be concluded that there is a continuous variation of the mass flow ratio across the entire range of possible primary nozzle positions with a peak value somewhere in the midsection of the entry section.

The effect of primary to secondary stagnation pressure ratio upon the wallpressure distribution is shown in Figs. 11-12. The axial distance corresponding to the peak of the initial wall-pressure curve rise; $x / d_{t} \cong 12$ marks the location in which the primary stream strikes the wall.

The non-dimensional pressure parameter is markedly increase with increasing primary stagnation pressure as shown in Fig. 11, may indicate that, not only the wall pressure increases with the stagnation pressure ratio with the case of zero and non-zero nozzle spacing.

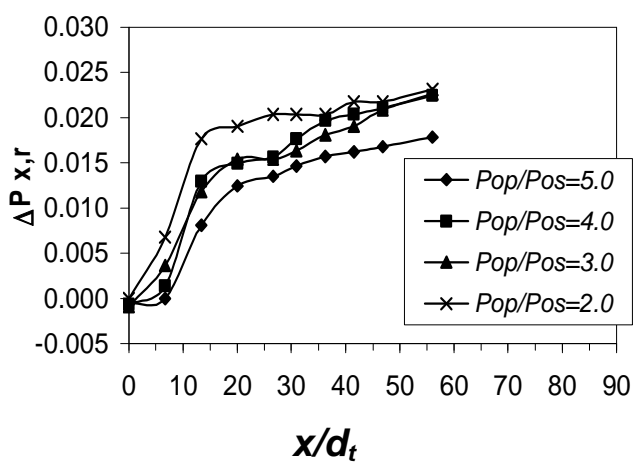

Figure 11: Pressure variations along the mixing chamber, C primary nozzle, L/D $=11.54, S / D=0.25$.

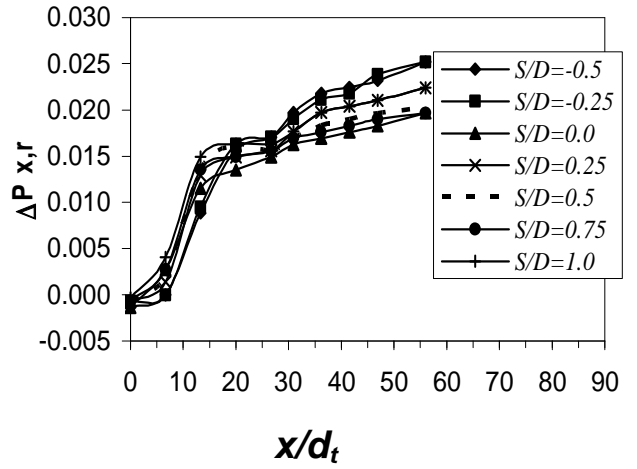

Figure 12: Effect of nozzle spacing on the pressure distribution, $C$ primary nozzle, $P o p / P o s=4.0, L / D=11.54$.

The effect of nozzle spacing on axial wall pressure distributions is shown in Fig. 12. When examining Figs. 10 and 12, it may be concluded that close to optimum nozzle spacing, ejector will have low pressure parameter. This may be due to higher mixing jet momentum.

It was mentioned in [8] that the efficiency of an air-ejector; $\eta$ may be defined as:

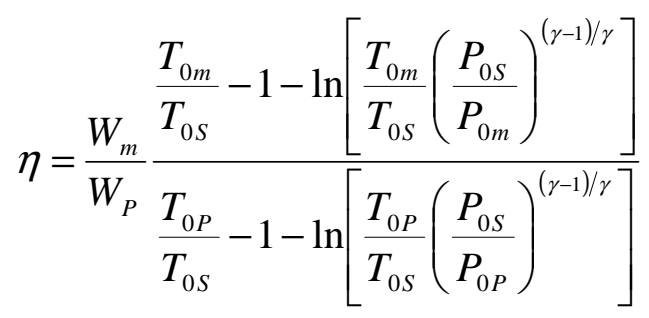

where, $\gamma$ is the ratio of specific heats. The ratio of the mass flow rates; $W_{m} / W_{P}$ is evaluated using the following relation 


$$
W_{m} / W_{P}=1+\bar{W}
$$

where, $\bar{W}=W_{S} / W_{P}$ is the mass flow ratio

The stagnation pressure; $P_{O m}$ is measured downstream the diffuser. The stagnation temperature of the mixed flow; $T_{o m}$ is evaluated using the energy equation:

$$
T_{0 m}=\left(T_{0 P}+\bar{W} T_{0 S}\right) /\left(W_{m} / W_{P}\right)
$$

Efficiency curves for the air ejector having cylindrical length-to-diameter ratio; $L / D$ of 11.54 are shown in Fig. 13. It may be observed that there is slight increase of efficiency when increasing mass flow ratio. Hence; it may be concluded from Figs. $\mathbf{9}$ and $\mathbf{1 3}$ that low stagnation pressure ratio ejectors have higher efficiency compared to higher stagnation pressure ratio ones. However; by examining Fig. 13, it can be seen that the efficiency increases with decreasing the spacing (approaching zero).

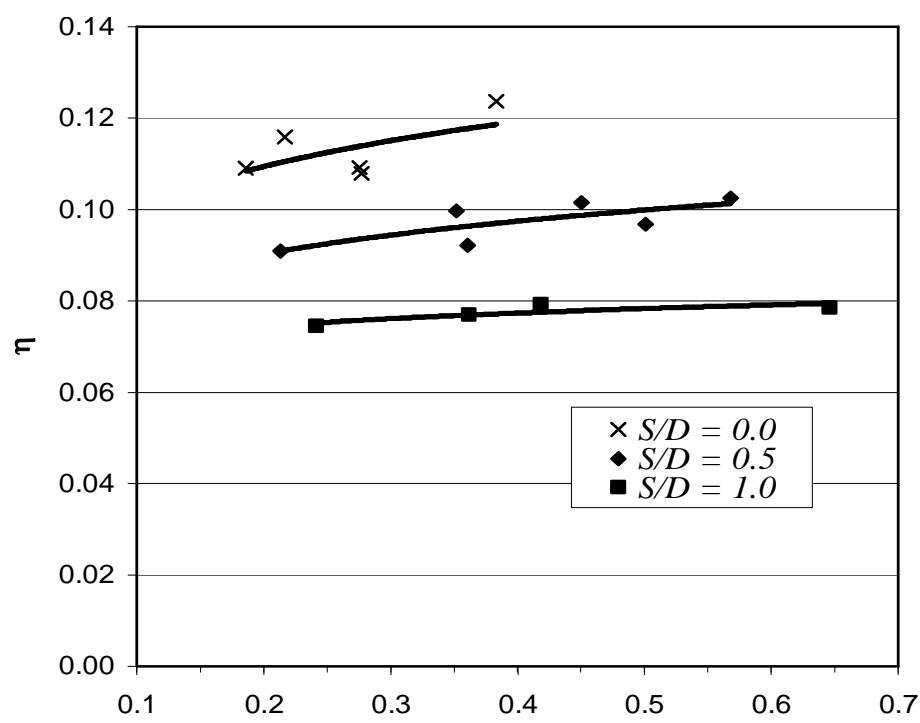

$\left(W_{S} / W_{P}\right) *\left(P_{b} / P_{O S}\right)$

Figure 13: Ejector efficiency characteristics, $C$ primary nozzle, $L / D=11.54$.

\section{CONCLUSIONS}

Performance investigations were conducted in constant area-mixing-section ejectors employing both convergent and convergent-divergent nozzles using unheated air. The device was tested at a primary pressure between 1.5 and 3 bar, cylindrical length-to-diameter ratio varying from 2.31 to 23.08 , and zero nozzle spacing. The tested ejector results were cross-plotted in order to show the performance of ejectors with configurations within the investigated ranges. 
The pressure variations along the mixing chamber were investigated allowing an appreciation of the influence of the cylindrical length-to-diameter ratio. The experimental results showed that secondary to primary mass flow rate ratio varied with the mixing chamber length-to-diameter ratio. Of the eight mixing chambers tested, the 13.85 length-to-diameter ratio exhibited better entrainment capability (i.e $\max$ $\bar{W}$ ratios). The $L / \mathrm{D}=2.31$ cylindrical length-to-throat diameter ratio ejector is too short for complete mixing and $L / \mathrm{D}>13.85$ cylindrical length-to-throat diameter ratio ejectors are too long and suffer frictional losses. The ejectors investigated conducted secondary air flows of less than 50 per-cent of the primary air flow when the secondary pressure was nearly equal to atmospheric pressure.

Further tests are conducted for ejector having convergent nozzle, cylindrical length-to-diameter ratio of 11.54 , and a range of spacing and pressure ratios. It may be concluded from the experiments that there is a continuous variation of the mass-flow ratio across the entire range of possible primary nozzle positions with a peak value somewhere when the primary flow spread impinges at the leading edge of the cylindrical section. It may be concluded also that the low stagnation pressure ratio ejectors have higher efficiency compared to those having higher stagnation pressure ratios.

\section{REFERENCES}

[1] Alperin, M. and Wu, J. J., "Thrust augmenting ejectors, Part I", AIAA Journal, 21 (10), (1983), 1428-1436.

[2] Chou, S. K., "Experimental studies on an air-air jet exhaust pump", ASHRAE Transactions, vol. 4, pt 2A, (1986), pp. 497-506.

[3] Chou, S. K., Yang, P. R. and Yap, C., "Maximum mass flow ratio due to secondary flow choking in an ejector refrigeration system", International Journal of Refrigeration, 24, (2001), 486-499.

[4] Dutton, J. C., Mikkelsen, C.D. and Addy, A. L., "A theoretical and experimental investigation of the constant area, supersonic-supersonic ejector", AIAA Journal, 20 (10), (1982), 1392-1400.

[5] Donald, P. H. and Gubbison, R. W., "Investigation at supersonic and subsonic Mach numbers of auxiliary inlets supplying secondary air flow to ejector exhaust nozzles", NACA RM E55J12a, Jan. (1956).

[6] Aissa, W. A., "Effect of multiple nozzles on air Ejector performance", $17^{\text {th }}$ International Symposium on Airbreathing Engines, ISABE 2005-1291., Munich, Germany, Sept. (2005).

[7] Okai, K. , Taguchi, H. and Futamura, H., "Experimental and numerical investigations of ejector and mixing effects in a model ejector ramjet configuration", 16th International Symposium on Airbreathing Engines, ISABE 2003-1230, Cleveland, USA, Sept. (2003).

[8] Schetz, J. A. and Fuhs, A. E., "Handbook of fluid dynamics and fluid machinery", Vol. III, John Wiley \& Sons, Inc., (1996), ISBN 0-471-14090-2.

[9] Aissa, W. A., "Effect of Throat Length on the Performance of an Air Ejector", $16^{\text {th }}$ International Symposium on Airbreathing Engines, ISABE 2003-1121, Cleveland, Ohio, USA, Sept. (2003). 


\section{استقصاء معملي لأداء المضخة النافورية}

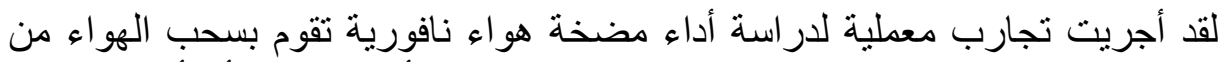

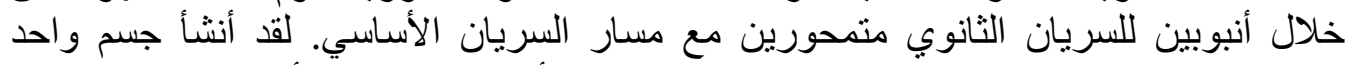

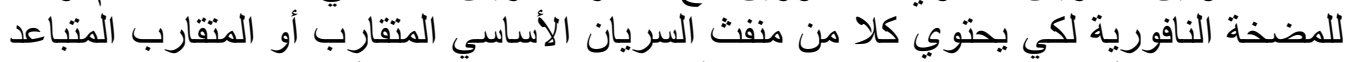

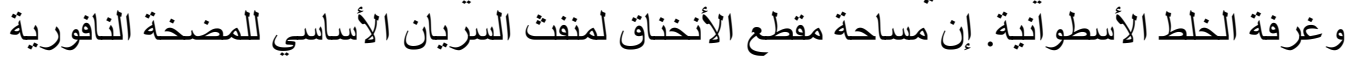

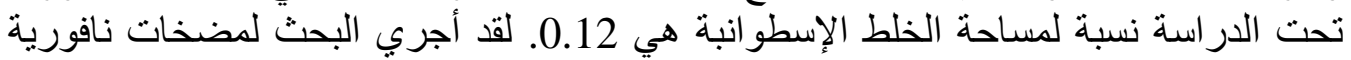

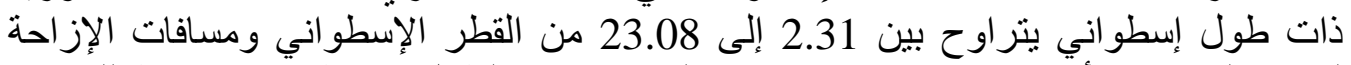

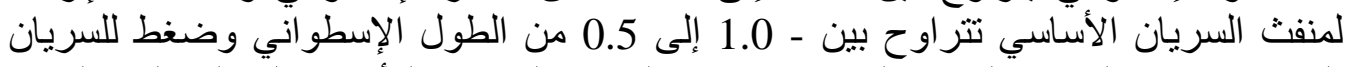

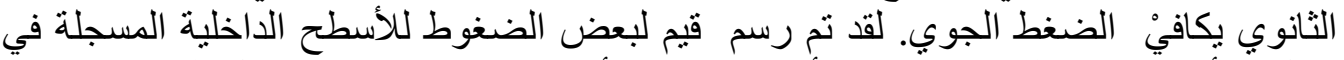

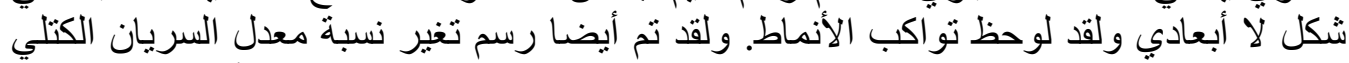

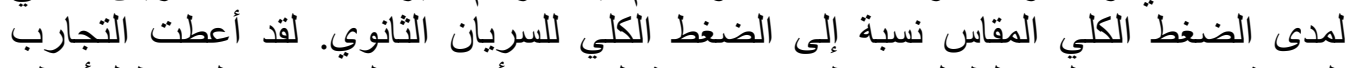

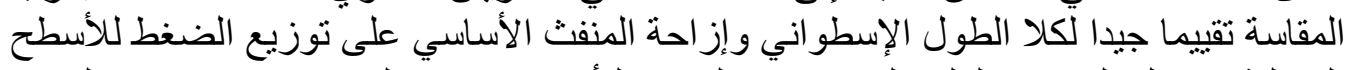

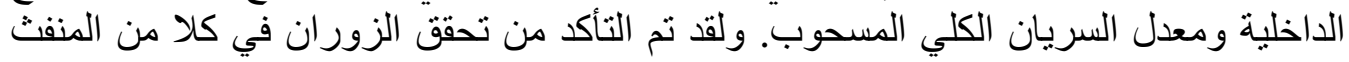
المتقارب و المنفث المتقارب المئر المتباعد. 